\title{
Sunitinib Dose Escalation in Metastatic Renal Cell Carcinoma
}

\author{
Andreas Bruchbacher ${ }^{\mathrm{a}, *}$, Sebastian Nachbargauer ${ }^{\mathrm{a}}$, Harun Fajkovic ${ }^{\mathrm{b}}$ and Manuela Schmidinger ${ }^{\mathrm{a}}$ \\ ${ }^{a}$ Department of Medicine I, Clinical Division of Oncology and Comprehensive Cancer Center, Medical University \\ of Vienna, Austria \\ ${ }^{\mathrm{b}}$ Department of Urology, Medical University of Vienna, Austria
}

Received 31 December 2018

Accepted 3 April 2019

\begin{abstract}
.
Background and objective: Sunitinib has been a standard treatment for patients with metastatic renal cell carcinoma (mRCC) since 2006. However, almost all patients will eventually progress. Besides well described mechanisms of primary or secondary resistance, insufficient drug exposure may lead to disease progression. The aim of this study was to identify patients in whom sunitinib dose escalation was performed and to analyse safety and efficacy of this strategy in clinical practice.

Methods: A single-centre retrospective study on dose escalation in $\mathrm{mRCC}$ patients who were treated with sunitinib at the Medical University of Vienna between January 2011 and May 2016. Dose escalation was studied in patients who had either progressed (cohort 1: $\mathrm{PD}^{\text {escal }}$ ) or had stable disease with minor progression (cohort 2: $\mathrm{SD}^{\text {escal }}$ ). The primary endpoints were response rate before and after dose escalation, global progression free survival and overall survival. Secondary endpoints were treatment duration before and after dose escalation and toxicity.

Results: Dose escalation up to $75 \mathrm{mg}$ was offered in 21 out of 265 patients. Response rates before and after dose escalation were $42,8 \%$ and $23.8 \%$, respectively. The median global PFS and OS were 15.60 and 32.95 months, respectively. The median treatment duration before and after dose escalation was 6.1 months (1.3-29.3 months) and 6.6 months (2.5-16.6 months). No new toxicities emerged under escalated dose and no grade 4 adverse events occurred.
\end{abstract}

Conclusion: Sunitinib dose escalation may be a strategy in patients with few toxicities at the time point of progression.

Keywords: Metastatic renal cell carcinoma, sunitinib, dose escalation, resistance

\section{LIST OF ABBREVIATIONS}

mRCC Metastatic renal cell carcinoma

PFS Progression free survival

ORR Objective response rates

TD Treatment duration

OS Overall survival

MTD Maximum tolerated dose
RECIST Response Evaluation Criteria in Solid Tumors

PDX Patient derived xenograft

$\mathrm{PD}^{\text {escal }}$ Progression with conventional dose with minor/manageable toxicity

$\mathrm{SD}^{\text {escal }} \quad$ Stable disease with conventional dose with minor/manageable toxicity

TD $D^{\text {escal }}$ Treatment duration at escalated dose

CTCAE Common terminology criteria for adverse events

\footnotetext{
${ }^{*}$ Correspondence to: Andreas Bruchbacher, MD, Department of Medicine I, Clinical Division of Oncology and Comprehensive Cancer Center, Medical University of Vienna, Waehringer Gürtel 18-20, A-1090 Vienna, Austria. Tel.: +43 140400 43290; Fax: +43 14040044610; E-mail: andreas.bruchbacher@meduniwien.ac.at.
}

\section{BACKGROUND}

The tyrosine kinase inhibitor sunitinib has been a standard of care in the 1st-line treatment of mRCC 
for more than a decade [1-5]. The recommended dose is $50 \mathrm{mg}$ once daily for 4 weeks followed by a 2 weeks break [4, 6]. However, in clinical practice, only few patients have been able to tolerate more than $50 \mathrm{mg}$. Dose reduction below $50 \mathrm{mg}$ has been reported in more than one third of patients [7]. This is the result of a well-known side effect profile of the drug, which includes hypertension, hand-foot syndrome, diarrhoea and fatigue. In the pivotal phase III trial [4] $38 \%$ and $32 \%$ patients in the sunitinib arm required dose interruptions and reductions, respectively.

However, dose reduction as a strategy to improve drug safety is a double-edged sword, since insufficient drug exposure might also lead to limited efficacy: Lankheet et al. have shown that only 50\% of mRCC patients under sunitinib standard dosing reach an adequate trough plasma concentration level, i.e. at least $50 \mathrm{ng} / \mathrm{ml}$. Hence, half of the population did not reach the predefined target level for anti-tumoral treatment. Though these measurements were done in small groups of 23-30 patients, they show that the recommended sunitinib dose might not be sufficient for all mRCC patients $[8,9]$.

Indeed, dose maintenance was shown to have a substantial impact on objective response and progression free survival: a pharmacokinetic and pharmacodynamic meta-analysis of six trials revealed that sunitinib exposure is strongly associated with response rates, time to progression and OS [10]. Insufficient drug exposure in individual patients may feign secondary drug resistance.

Resistance to sunitinib was shown to occur after a median treatment duration of 11 months [5] and is ultimately leading to a change of treatment. Burotto and colleagues [11] raised the question as to whether progression according to the Response Evaluation Criteria in Solid Tumors (RECIST) indicates drug resistance. By estimating the growth and regression rates and the stability of growth using data from the pivotal sunitinib phase III trial, the authors observed a prolonged stability of growth with sunitinib in the majority of patients. According to their findings, the median growth rate was stable for a median of 275 days on therapy and remained stable beyond 300, 600 and 900 days in 122, 65 and 27 patients, respectively. Based on these findings, they further suggested that patients may derive prolonged benefits from the drug if treated beyond RECIST-documented progression. Taking together this data and the impact of dosing on outcome, dose escalation beyond radiological pro- gression might be an option to delay a change of treatment.

Identifying patients in whom treatment beyond progression is reasonable may be challenging. In this context, the predictive value of sunitinib-induced toxicities may help to guide treatment decisions. Patients experiencing toxicities were shown to derive greater benefits from the drug when compared to patients without [12-14]. These findings suggest that the development of side effects reflects adequate individual drug exposure. Consequently, progression in the context of limited toxicities may indicate insufficient drug exposure rather than primary or secondary drug resistance. These findings suggest that dose escalation may be offered in these patients at the time point of disease progression.

The aim of this retrospective analysis was to identify and analyse outcomes of patients treated at the Medical University of Vienna in whom dose escalation was performed at the time point of disease progression or in the context of stable disease with minor progression (non RECIST progression).

\section{PATIENTS AND METHODS}

This is a single-centred cohort review to investigate safety and efficacy of sunitinib dose escalation. Data has been collected in the central database from patients with $\mathrm{mRCC}$ who were treated with sunitinib at the Department for Oncology, Medical University of Vienna. This study was approved by the ethical review committee of the Medical University of Vienna.

All patients with mRCC treated with sunitinib between January 2010 and May 2016 were analysed for dose escalation. Patients were eligible if they had undergone dose escalations to 62.5 or $75 \mathrm{mg}$ during their course of sunitinib treatment. Dose escalations were performed in the context of no/limited toxicity at the time point of staging and disease progression or stable disease. Dose reduction were performed whenever the patient or treating physician perceived a side effect as non-manageable despite prophylactic and supportive measures, not necessarily based on the grade of toxicity. The Memorial Sloan-Kettering Cancer (MSKCC) score was used to determine the patient's risk group. Two patient's cohorts were defined depending on the reason for dose escalation: cohort 1: dose escalation in the setting of RECIST-disease progression 
with conventional dose and minor/manageable toxicity $\left(\mathrm{PD}^{\mathrm{escal}}\right)$ and cohort 2: stable disease with minor progression (non-RECIST-PD) on conventional dose and minor/manageable toxicity ( $\mathrm{SD}^{\mathrm{escal}}$ ). Minor/manageable toxicity has been defined as low grade adverse events (grade 1 and 2) and/or grade 3 adverse events which easily were manageable with concomitant medication (eg. Hypertension) and without dose reduction. All data on adverse events were collected retrospectively by reviewing clinical charts. Within these files, all typical TKI-associated toxicities are assessed and graded according to CTCAE version 4.0. There were no formal guidelines regarding assessment of toxicity or response for the study, but toxicity is routinely assessed in CTCAE criteria at our department. Whenever possible, RECIST criteria were used to assess response before dose escalation, however not all patient could be staged according to RECIST criteria due to the real world setting of this study (most of them had their CT or MRI scans outside of the hospital, where RECIST Staging is not performed routinely).

Primary endpoints were:

1) Response rates a) prior dose escalation and b) at escalated dose.

2) Global PFS (before and after dose escalation).

3) Overall survival in patients with dose escalation.

Secondary endpoints were:

1. Treatment duration before and after dose escalation $\left(\mathrm{TD}^{\text {escal }}\right)$

2. Toxicity differences between conventional and escalated dose (common terminology criteria for adverse events (CTCAE) version 4.0.)

Sunitinib treatment was continued until unacceptable toxicity and/or disease progression without the option for further dose escalation.

\section{STATISTICAL ANALYSIS}

PFS and OS were calculated from the start of sunitinib at conventional dose until progression under sunitinib at escalated dose or death. Survival was calculated using the Kaplan-Meier method. Cohorts 1 and 2 were compared with the log-rank test. Patient characteristics were compared between the different groups by using Qui Square test and Mann Whitney $\mathrm{U}$ test, due to small group size. Multivariate analyses

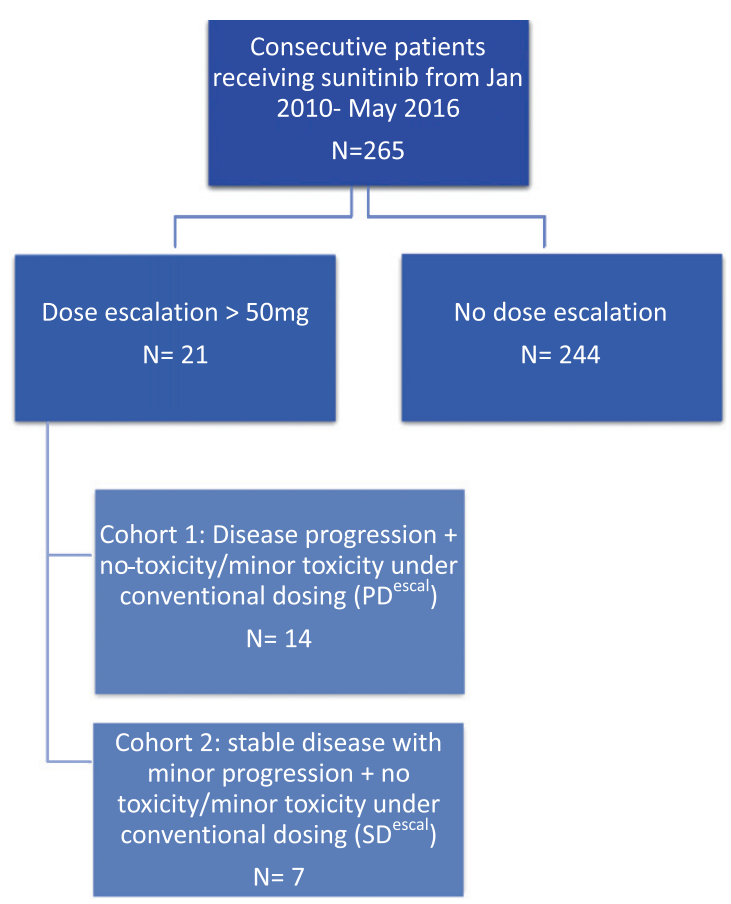

Fig. 1. Screening tree.

were performed with Cox-Regression. A two-sided $p$-value lower or equal 0.05 represents significance in all tests. The treatment duration on escalated treatment dose for all patients with dose escalations $\left(\mathrm{TD}^{\text {escal }}\right)$ was calculated from start of escalated dose $(62.5 \mathrm{mg}$ or $75 \mathrm{mg})$ until end of sunitinib treatment at escalated dose.

\section{RESULTS}

Twenty-one out of 265 patients treated with sunitinib between January 2010 May 2016 were identified and included in this analysis (Fig. 1). The patient's characteristics are displayed in Table 1. The median age at start of sunitinib therapy was 56 years. All but one patient had undergone prior nephrectomy.

$14.3 \%$ of all patients were on a traditional schedule (4 weeks on- 2 weeks off) while undergoing dose escalation. $57.1 \%$ were on a 2 weeks on- 1 week off schedule and $28.6 \%$ of all patients had other schedules such as 10 days on - 5 days off, 7 days on - 2 days off or 5 days on - 2 days off during the whole course of therapy.

All patients were initially treated with $50 \mathrm{mg}$ sunitinib. Fourteen patients $(66.7 \%)$ were in cohort 
Table 1

Patients characteristics

\begin{tabular}{|c|c|c|c|}
\hline \multicolumn{2}{|c|}{ Patients characteristics $(\mathrm{N}=21)$} & \multirow[t]{2}{*}{$\mathrm{N}$} & \multirow[t]{2}{*}{$\%$} \\
\hline Median Age & 56 & & \\
\hline \multirow[t]{2}{*}{ Gender } & female & 18 & $85.7 \%$ \\
\hline & male & 3 & $14.3 \%$ \\
\hline \multirow[t]{2}{*}{ Clear cell histology } & yes & 17 & $81.0 \%$ \\
\hline & no & 4 & $19.0 \%$ \\
\hline \multirow[t]{3}{*}{ MSKCC risk } & favourable & 5 & $23.8 \%$ \\
\hline & intermediate & 16 & $76.2 \%$ \\
\hline & poor & 0 & $.0 \%$ \\
\hline \multirow[t]{2}{*}{ Nephrectomy } & yes & 20 & $95.2 \%$ \\
\hline & no & 1 & $4.8 \%$ \\
\hline \multirow{5}{*}{$\begin{array}{l}\text { Treatment line in } \\
\text { which Sunitinib was } \\
\text { prescribed }\end{array}$} & first & 15 & $71.4 \%$ \\
\hline & second & 1 & $4.8 \%$ \\
\hline & third & 2 & $9.5 \%$ \\
\hline & fourth & 2 & $9.5 \%$ \\
\hline & sixth & 1 & $4.8 \%$ \\
\hline $\begin{array}{l}\text { Additional local } \\
\text { treatment }\end{array}$ & yes & 9 & $42.9 \%$ \\
\hline $\begin{array}{l}\text { (e.g. metastasectomy, } \\
\text { stereotactic } \\
\text { radiosurgery, }\end{array}$ & no & 12 & $57.1 \%$ \\
\hline \multicolumn{4}{|l|}{$\begin{array}{l}\text { radiofrequency } \\
\text { ablation) during the } \\
\text { entire course of } \\
\text { disease }\end{array}$} \\
\hline \multirow[t]{3}{*}{ Metastatic sites, $\mathrm{n}$} & 1 & 4 & $19.0 \%$ \\
\hline & 2 & 6 & $28.6 \%$ \\
\hline & 3 or more & 11 & $52.4 \%$ \\
\hline
\end{tabular}

1 (PD $\left.{ }^{\text {escal }}\right)$ and $7(33.3 \%)$ in cohort $2\left(\mathrm{SD}^{\mathrm{escal}}\right)$. Nineteen patients were primary escalated up to $62.5 \mathrm{mg}$, of which 9 were further escalated to $75 \mathrm{mg}$ either because of low toxicity or insufficient response. Two patients were escalated directly from up $50 \mathrm{mg}$ up to $75 \mathrm{mg}$ because of total lack of toxicity and good performance status. Eleven patients were not escalated beyond $62.5 \mathrm{mg}$ due to adverse events.

\section{RESPONSE}

Prior dose escalation, objective responses or stable disease were observed in $42.8 \%(n=9)$ and 47.6 $\%(n=10)$ of patients, respectively, while 2 patients (9.5\%) had progressive disease as best response.

After dose escalation, 5 out of 21 patients achieved an objective response $(23,8 \%)$ of which one patient had a complete remission; another 10 patients (47.6\%) had SD. Among the different cohorts, 4 patients in the $\mathrm{PD}^{\text {escal }}$ and one patient in the $\mathrm{SD}^{\text {escal }}$ achieved an objective response; the clinical benefit (CR, PR, SD) rate after dose escalation was $71.4 \%$ and similar for both cohorts.

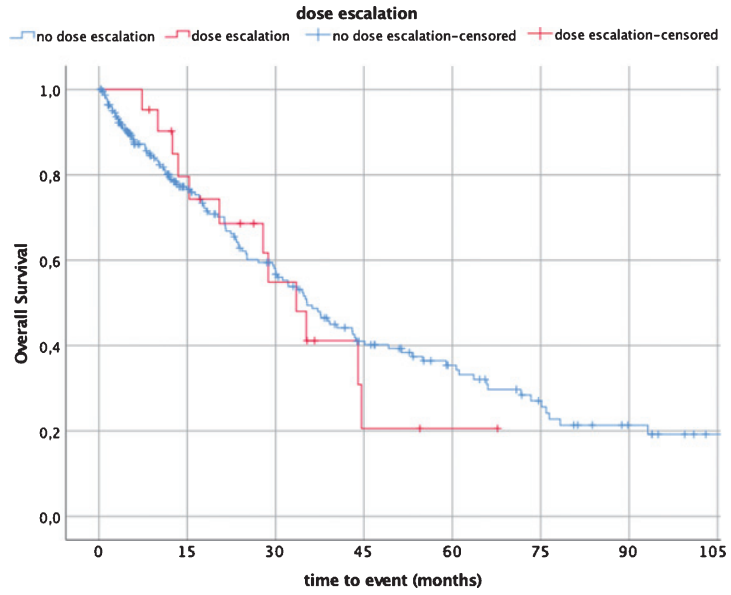

Fig. 2. Median overall survival (OS) dose escalation (21 patients) vs non-dose escalation (227 patients).

\section{GLOBAL PROGRESSION FREE SURVIVAL}

The median global progression free survival (PFS) for all 21 patients was 15.6 months (95\% CI: 9.5-21.8) (Fig. 2). The median global PFS for PD ${ }^{\text {escal }}$ and SD $^{\text {escal }}$ was 15.6 months (95\%CI: 8.0-23.2) and 16.4 months (95\% Confidence Interval: 8.8-24.0), respectively. Three patients were too early for PFS analysis ( 1 patient had a CR and 2 patients were still on treatment at the time of cut off).

\section{SURVIVAL}

The median overall survival (OS) for the entire dose escalated population was 32.95 months $(95 \%$ Confidence Interval (CI): 24.4-41.5).

The median OS for the $\mathrm{PD}^{\text {escal }}$ and $\mathrm{SD}^{\text {escal }}$ cohorts was 43.3 months (95\% CI: 23.0-63.6) and 27.4 months (95\% Confidence Interval: 0.0-58.4), respectively.

The median OS for the no-dose escalation cohort was 35.3 months (95\% Confidence Interval (CI): 29.3-41.4) $(\mathrm{N}=227)$.

\section{TREATMENT DURATION WITH CONVENTIONAL AND ESCALATED DOSE}

The median treatment duration with conventional dose and escalated dose was 6.1 months (range: 1.3-29.3 months) and 6.6 months (range: $2.5-16.6$ months) for all patients, respectively. Two patients 
were still on dose escalation at the time of analysis. The median treatment duration for cohorts $\mathrm{PD}^{\text {escal }}$ and $\mathrm{SD}^{\text {escal }}$ was 6.6 months and 6.1 months, respectively.

\section{TOXICITY}

Incidence and grade of toxicities at conventional and at escalated dose are displayed in Table 2. The most common adverse events for both sunitinib conventional dose and escalated dose were hypertension $(81 \%$, grade $3: 33.3 \%)$, fatigue (71\%, grade $3: 42.9 \%)$, stomatitis $(57.1 \%$, grade $3: 4.8 \%)$, diarrhoea $(52.4 \%$, grade $3: 19.0 \%$ ), hypothyroidism (42.9\%) and thrombocytopenia (42.9\%). After dose-escalation, the most frequent grade 1-2 toxicities followed a similar pattern. However, laboratory abnormalities such as hyperlipidemia, renal dysfunction and anemia were more frequent. No grade 4 adverse effects were observed.

\section{DISCUSSION}

The aim of this analysis was to investigate the safety and efficacy of sunitinib at a daily dose beyond $50 \mathrm{mg}$ per day in patients who had experienced either disease progression or stable disease with minor progression and who did have few or no toxicities at the time point of assessment. Sunitinib dose escalation resulted in a clinical benefit (CR, PD, SD) in the majority of patients $(71.4 \%)$. The median global PFS was 15.6 months (95\% CI 8.0-23.2). The median treatment duration at conventional dose was 6.1 months (1.3-29.3) and dose escalation added another 6.6 months (2.5-16.6) months, during which no disease progression was documented.

Dose escalation as a strategy to overcome sunitinib drug resistance was initially studied in two mice xenograft models. The first model RP-R-01 patientderived ccRCC xenograft (PDX) had a negative VHL gene, including gene aberrations in PBRM1, SETD2 and KDM6A. The second model RP-R-02 PDX was developed from a skin metastasis in a patient with hereditary VHL syndrome. Both lines were treated with the same therapy schedule 40-60$80 \mathrm{mg} / \mathrm{kg}$ sunitinib, 5 days a week. An incremental increase of sunitinib at the time point of disease progression restored the sensitivity of the tumor toward sunitinib in both PDX models. Similar findings have been reported from 16 patients in whom dose escalations up to $75 \mathrm{mg}$ were performed upon disease progression. A clinical benefit was observed in the majority of the patients [15].

Dose escalation as a strategy to optimize outcomes has been established early with the TKI axitinib. Escalation of axitinib upon occurrence of resistance was shown to enable another 10.1 months (range: 0.6-37.9 months) on treatment [16]. Drug exposure and individualized treatment schedules were also studied with other TKI's such as Pazopanib [17]. According to a retrospective analysis, a minimum dose threshold of $\geq 20.5 \mathrm{mg} / \mathrm{L}$ was significantly associated with prolonged PFS and tumor shrinkage [18]. In a prospective trial on a pharmacokinetically guided individualized dosing algorithm, 17 out of 30 patients needed a dose adjustment in terms of dose escalation to achieve the above-mentioned threshold of $\geq 20.5 \mathrm{ml} / \mathrm{L}$ [19].

Interestingly, these strategies have been less commonly considered with sunitinib even though evidence exists that sunitinib can be escalated up to $75 \mathrm{mg}$ [6]. Furthermore, according to the prescribing information for sunitinib, individual dose modifications can be increased up to $87.5 \mathrm{mg}$ if used in combination with a strong CYP 3A4 inducers [20]. Our findings are consistent with previously published reports on sunitinib dose escalation, using sunitinib, either at $62.5 \mathrm{mg}$ or $75 \mathrm{mg}$ [21-23]. Adelaiye et al. demonstrated that sunitinib dose escalation can overcome drug resistance in both mouse RCC xenografts and selected patients with appropriate toxicity profile [15]. Raphael et al. reported on $25 \mathrm{mRCC}$ patients who were offered sunitinib dose escalation upon occurrence of resistance. In total, these patients had an added median PFS of 6.7 months after initial progression under standard dosing [24]. Bjarnason et al investigated in a prospective phase II trial the efficacy and safety of sunitinib given in an individualized schedule. Twenty out of 117 untreated mRCC patients were escalated above $50 \mathrm{mg}$ (12 patients up to $62.5 \mathrm{mg}$ and 6 patients up to $75 \mathrm{mg}$ ) in case of low toxicity ( $\leq$ grade 1 toxicity). The whole patient population reached a PFS of 12.5 months and an OS of 38.5 months. This data supports the idea of individualized scheduling to reach the maximum benefit in sunitinib therapy [25].

Dose escalation is a strategy that requires careful patient monitoring and pro-active side effect management. Concerns regarding potential toxicities may prevent physicians from considering dose escalation as a valid therapeutic strategy. However, it was shown that the incidence and severity of adverse events can be considerably reduced by individualizing the 
Table 2

Incidence and severity of toxicities

\begin{tabular}{|c|c|c|c|c|c|c|c|c|c|c|c|c|}
\hline \multirow{3}{*}{$\begin{array}{l}\text { Variable } \\
\text { Fatigue }\end{array}$} & \multicolumn{4}{|c|}{ Conventional dose $(\mathrm{N}=21)$} & \multicolumn{4}{|c|}{ Escalated dose $62.5 \mathrm{mg}(\mathrm{N}=19)$} & \multicolumn{4}{|c|}{ Escalated dose $75 \mathrm{mg}(\mathrm{N}=10)$} \\
\hline & \multicolumn{2}{|c|}{$\begin{array}{c}\text { Grade } 1-3 \\
n \%\end{array}$} & \multicolumn{2}{|r|}{$\begin{array}{c}\text { Grade } 3 \\
n \%\end{array}$} & \multicolumn{2}{|c|}{$\begin{array}{c}\text { Grade } 1-3 \\
n \%\end{array}$} & \multicolumn{2}{|c|}{$\begin{array}{c}\text { Grade } 3 \\
n \% \\
\end{array}$} & \multicolumn{2}{|c|}{$\begin{array}{c}\text { Grade } 1-3 \\
n \%\end{array}$} & \multicolumn{2}{|r|}{$\begin{array}{c}\text { Grade } 3 \\
n \% \\
\end{array}$} \\
\hline & 15 & $71.4 \%$ & 9 & $42.9 \%$ & 14 & $73.7 \%$ & 10 & $52.6 \%$ & 7 & $70.0 \%$ & 5 & $50.0 \%$ \\
\hline Hypertension & 17 & $81.0 \%$ & 7 & $33.3 \%$ & 14 & $73.7 \%$ & 3 & $15.8 \%$ & 8 & $80.0 \%$ & 2 & $20.0 \%$ \\
\hline Diarrhoea & 11 & $52.4 \%$ & 4 & $19.0 \%$ & 13 & $68.4 \%$ & 1 & $5.3 \%$ & 6 & $60.0 \%$ & 2 & $20.0 \%$ \\
\hline $\mathrm{H} / \mathrm{F}$ syndrome & 7 & $33.3 \%$ & 3 & $14.3 \%$ & 7 & $36.8 \%$ & 1 & $5.3 \%$ & 3 & $30.0 \%$ & 1 & $10.0 \%$ \\
\hline Stomatitis & 12 & $57.1 \%$ & 1 & $4.8 \%$ & 8 & $42.1 \%$ & 0 & $0.0 \%$ & 3 & $30.0 \%$ & 1 & $10.0 \%$ \\
\hline Nausea & 7 & $33.3 \%$ & 1 & $4.8 \%$ & 8 & $42.1 \%$ & 0 & $0.0 \%$ & 6 & $60.0 \%$ & 0 & $0.0 \%$ \\
\hline Hypothyreosis & 9 & $42.9 \%$ & 0 & $0.0 \%$ & 12 & $63.2 \%$ & 0 & $0.0 \%$ & 3 & $30.0 \%$ & 0 & $0.0 \%$ \\
\hline Thrombocytopenia & 9 & $42.9 \%$ & 0 & $0.0 \%$ & 9 & $47.4 \%$ & 0 & $0.0 \%$ & 3 & $30.0 \%$ & 0 & $0.0 \%$ \\
\hline Leukopenia & 8 & $38.1 \%$ & 0 & $0.0 \%$ & 6 & $31.6 \%$ & 0 & $0.0 \%$ & 4 & $40.0 \%$ & 0 & $0.0 \%$ \\
\hline Hypertriglyceridemia & 7 & $33.3 \%$ & 0 & $0.0 \%$ & 12 & $63.2 \%$ & 0 & $0.0 \%$ & 8 & $80.0 \%$ & 0 & $0.0 \%$ \\
\hline Anaemia & 4 & $19.0 \%$ & 0 & $0.0 \%$ & 8 & $42.1 \%$ & 0 & $0.0 \%$ & 2 & $20.0 \%$ & 0 & $0.0 \%$ \\
\hline Renal dysfunction & 5 & $23.8 \%$ & 0 & $0.0 \%$ & 10 & $52.6 \%$ & 0 & $0.0 \%$ & 6 & $60.0 \%$ & 0 & $0.0 \%$ \\
\hline Liver & 3 & $14.3 \%$ & 0 & $0.0 \%$ & 5 & $26.3 \%$ & 0 & $0.0 \%$ & 2 & $20.0 \%$ & 0 & $0.0 \%$ \\
\hline Anorexia & 5 & $23.8 \%$ & 1 & $4.8 \%$ & 3 & $15.8 \%$ & 0 & $0.0 \%$ & 3 & $30.0 \%$ & 0 & $0.0 \%$ \\
\hline Rash & 2 & $9.5 \%$ & 0 & $0.0 \%$ & 1 & $5.3 \%$ & 0 & $0.0 \%$ & 0 & $0.0 \%$ & 0 & $0.0 \%$ \\
\hline LVEF reduction & 1 & $4.8 \%$ & 0 & $0.0 \%$ & 0 & $0.0 \%$ & 0 & $0.0 \%$ & 1 & $10.0 \%$ & 0 & $0.0 \%$ \\
\hline
\end{tabular}

Toxicity profile as per CTCAE 4.0 , standard dose and escalated dose $(62.5 \mathrm{mg}$ and $75 \mathrm{mg})$.

treatment schedule [26-28]. Bracarda et al. reported that the incidence of severe adverse events (grade $\geq 3$ ) was significantly reduced by switching to the $2 / 1$ schedule, compared with the incidence reported during the initial $4 / 2$ schedule (maximum toxicity grade $\geq 3: 45.7 \%$ during the traditional $4 / 2$ schedule versus $8.2 \%$ during alternative $2 / 1$ schedule) [29]. In addition, Bjarnason et al. reported that patients treated with individualized dose/schedule had a longer PFS when compared to patients on the traditional $4 / 2$ schedule (PFS 10.9 months and 5.3 months, respectively) [30]. This data suggests that an alternative schedule of sunitinib is more likely to enable dose escalation. In our study, only 3 out of 21 patients were treated with the traditional schedule, while 18 were on an alternative schedule (either 2 weeks on-1 week off or another individualized schedule, e.g. 7 days on-4 days off).

Distinguishing between the type of side effect appears important in the context of dose escalation: some side effects may be easily controlled with co-medication, such as hypertension. Others might be dose limiting, because no appropriate supportive measures exist, such as stomatitis and fatigue. In our analysis, hypertension was the most common adverse event upon dose escalation $(73.7 \%$ and $80 \%$ of patients with $62.5 \mathrm{mg}$ and $75 \mathrm{mg}$, respectively), followed by fatigue, diarrhoea and hyperlipidemia, occurring in 73.7, 68.4 and $63.2 \%$ of patients on $62.5 \mathrm{mg}$ and in 70,60 and $80 \%$ of patients on $75 \mathrm{mg}$ treatment dose, respectively. No grade 4 adverse events occurred. Only one patient had to discontinue sunitinib on escalated dose due to grade 3 fatigue, asthenia and hypertension. Another patient required dose reduction from $75 \mathrm{mg}$ to $62.5 \mathrm{mg}$, which he was then able to maintain for 9 months.

Considering that patients with dose escalation were mostly intermediate risk, the median OS of 32.95 months is encouraging and longer than reported previously for this patient population. Furthermore, it reached the median OS of the entire no-dose escalation cohort $(\mathrm{N}=227)$ (35.3 months, 95\% Confidence Interval (CI): 29.3-41.4) (Fig. 2).

The limitations of this study are first, that it is a single centre retrospective analysis with a low number of patients. Second, the patient population is heterogeneous in terms of treatment line. Third, almost half of our patients had undergone additional local treatments at some time point during the course of the disease, which may have contributed to prolonged OS and PFS.

It can be questioned as to whether sunitinib dose escalation remains important as a strategy today, given the considerable amount of agents that have been developed for second- and later lines. Novel second-line agents were shown to specifically address mechanisms of anti-VEGFRresistance. Cabozantinib, a MET-AXL and VEGF inhibitor and the FGF-VEGF-inhibitor lenvatinib (in combination with everolimus) have been approved for 2nd-line based on statistically significant OS, PFS and ORR benefits, respectively [31,32]. Another new standard of care in second-line is the programmed 
cell death-1 immune check point inhibitor (ICI, PD1 inhibitor) nivolumab, which was shown to provide a statistically significant benefit in OS and ORR [33]. Furthermore, in 2019, immune check point inhibitor combinations have been recommended as a new standard of care in the majority of patients (intermediate and poor risk). Another paradigm change is expected with the introduction of TKI-check point inhibitor combinations [34].

Sunitinib dose escalation might remain either an option for favourable risk patients only or in regions where novel strategies are not approved yet. In this context, optimizing outcomes with available drugs may be of paramount importance. Thus, strategies such as treatment beyond progression and dose escalation may remain valid measures. Our data add further strength to the existing evidence on sunitinib dose escalation upon disease progression or insufficient response.

Prospective trials with larger patient populations are needed to verify the hypothesis of sunitinib dose escalation, however, due to competing interest with many novel strategies, it is unlikely that current research efforts will address this topic.

\section{ACKNOWLEDGMENTS}

The authors have no acknowledgments.

\section{CONFLICT OF INTERESTS}

Andreas Bruchbacher: Research grant from Pfizer and travel grant from EUSA pharma.

Manuela Schmidinger: Honoraria for lectures and advisory boards from Pfizer, Roche, Novartis, BMS, Ipsen, Eisai, Astellas and EUSA pharma.

Harun Fajkovic: Honoraria for lectures from Pfizer, Jansen, Ipsen and Astellas.

Sebastian Nachbargauer reported no conflicts of interest.

\section{REFERENCES}

[1] Thomas JS, Kabbinavar F. Metastatic clear cell renal cell carcinoma: A review of current therapies and novel immunotherapies. Critical Reviews in Oncology/ Hematology. 2015;96(3):527-33.

[2] Sun L, Liang C, Shirazian S, Zhou Y, Miller T, Cui J, et al. Discovery of 5-[5-fluoro-2-oxo-1,2-dihydroindol-(3Z)ylidenemethyl]-2,4-dimethyl-1H-pyrrole-3-carboxylic acid (2-diethylaminoethyl)amide, a novel tyrosine kinase inhibitor targeting vascular endothelial and platelet-derived growth factor receptor tyrosine kinase. J Med Chem. 2003;46(7):1116-9.
[3] Chow LQM, Eckhardt SG. Sunitinib: From rational design to clinical efficacy. Journal of Clinical Oncology. 2007;25(7):884-96.

[4] Motzer RJ, Hutson TE, Tomczak P, Michaelson MD, Bukowski RM, Rixe O, et al. Sunitinib versus interferon alfa in metastatic renal-cell carcinoma. New England Journal of Medicine. 2007;356(2):115-24.

[5] Motzer RJ, Hutson TE, Tomczak P, Michaelson MD, Bukowski RM, Oudard S, et al. Overall survival and updated results for sunitinib compared with interferon alfa in patients with metastatic renal cell carcinoma. Journal of Clinical Oncology. 2009;27(22):3584-90.

[6] Faivre S, Delbaldo C, Vera K, Robert C, Lozahic S, Lassau $\mathrm{N}$, et al. Safety, pharmacokinetic, and antitumor activity of SU11248, a novel oral multitarget tyrosine kinase inhibitor, in patients with cancer. J Clin Oncol. 2006;24(1): 25-35.

[7] Gore ME, Szczylik C, Porta C, Bracarda S, Bjarnason GA, Oudard S, et al. Final results from the large sunitinib global expanded-access trial in metastatic renal cell carcinoma. British Journal of Cancer. 2015;113(1):12-9.

[8] Lankheet NA, Knapen LM, Schellens JH, Beijnen JH, Steeghs N, Huitema AD. Plasma concentrations of tyrosine kinase inhibitors imatinib, erlotinib, and sunitinib in routine clinical outpatient cancer care. Ther Drug Monit. 2014;36(3):326-34.

[9] Lankheet NAG, Desar IME, Mulder SF, Burger DM, Kweekel DM, van Herpen CML, et al. Optimizing the dose in cancer patients treated with imatinib, sunitinib and pazopanib. British Journal of Clinical Pharmacology. 2017;83(10):2195-204.

[10] Houk BE, Bello CL, Poland B, Rosen LS, Demetri GD, Motzer RJ. Relationship between exposure to sunitinib and efficacy and tolerability endpoints in patients with cancer: Results of a pharmacokinetic/pharmacodynamic meta-analysis. Cancer Chemother Pharmacol. 2010;66(2): 357-71.

[11] Burotto M, Wilkerson J, Stein W, Motzer R, Bates S, Fojo $\mathrm{T}$. Continuing a cancer treatment despite tumor growth may be valuable: Sunitinib in renal cell carcinoma as example. PLoS One. 2014;9(5):e96316.

[12] Schmidinger M, Larkin J, Ravaud A. Experience with sunitinib in the treatment of metastatic renal cell carcinoma. Therapeutic Advances in Urology. 2012;4(5):253-65.

[13] Rini BI, Cohen DP, Lu DR, Chen I, Hariharan S, Gore ME, et al. Hypertension as a biomarker of efficacy in patients with metastatic renal cell carcinoma treated with sunitinib. JNCI Journal of the National Cancer Institute. 2011;103(9): 763-73.

[14] Donskov F, Michaelson MD, Puzanov I, Davis MP, Bjarnason GA, Motzer RJ, et al. Sunitinib-associated hypertension and neutropenia as efficacy biomarkers in metastatic renal cell carcinoma patients. British Journal of Cancer. 2015;113(11):1571-80.

[15] Adelaiye R, Ciamporcero E, Miles KM, Sotomayor P, Bard J, Tsompana M, et al. Sunitinib dose-escalation overcomes transient resistance in clear cell renal cell carcinoma and is associated with epigenetic modifications. Molecular Cancer Therapeutics. 2015;14(2):513-22.

[16] Ornstein MC, Wood L, Elson P, Allman K, Beach J, Martin A, et al. Clinical effect of dose escalation after disease progression in patients with metastatic renal cell carcinoma. Clin Genitourin Cancer. 2017;15(2):e275-e80.

[17] Verheijen RB, Beijnen JH, Schellens JHM, Huitema ADR, Steeghs N. Clinical pharmacokinetics and pharmacody- 
namics of pazopanib: Towards optimized dosing. Clin Pharmacokinet. 2017;56(9):987-97.

[18] Suttle AB, Ball HA, Molimard M, Hutson TE, Carpenter C, Rajagopalan D, et al. Relationships between pazopanib exposure and clinical safety and efficacy in patients with advanced renal cell carcinoma. Br J Cancer. 2014;111(10):1909-16.

[19] Verheijen RB, Bins S, Mathijssen RH, Lolkema MP, van Doorn L, Schellens JH, et al. Individualized pazopanib dosing: A prospective feasibility study in cancer patients. Clin Cancer Res. 2016;22(23):5738-46.

[20] Inc PLDP. SUTENT- sunitinib malate capsule 2006 http://labeling.pfizer.com/showlabeling.aspx id=607.

[21] Mitchell N, Fong PCC, Broom RJ. Clinical experience with sunitinib dose escalation in metastatic renal cell carcinoma. Asia-Pacific Journal of Clinical Oncology. 2015;11(3) :e1-e5.

[22] Guevremont C, Mija FI, Isbarn H, Jeldres C, Lughezzani G, Sun M, et al. Dose escalation of second-line sunitinib results in rapid partial remission of multiple hepatic metastases. Canadian Urological Association Journal. 2009;3(6): E92-E3.

[23] Shi H-Z, Tian J, Chen X, Wang D, Li C-1. Clinical experience of escalated sunitinib dose in select patients with metastatic renal cell carcinoma. Clinical Genitourinary Cancer. 2017;15(1):139-44.

[24] Raphael J, Thawer A, Bjarnason GA. Sunitinib doseescalation after disease progression in metastatic renal cell carcinoma. Urologic Oncology: Seminars and Original Investigations. 2018;36(1):12.e1-e6.

[25] Bjarnason GA, Knox JJ, Kollmannsberger CK, Soulieres D, Ernst DS, Zalewski P, et al. The efficacy and safety of sunitinib given on an individualised schedule as first-line therapy for metastatic renal cell carcinoma: A phase 2 clinical trial. Eur J Cancer. 2019;108:69-77.

[26] Najjar YG, Mittal K, Elson P, Wood L, Garcia JA, Dreicer $\mathrm{R}$, et al. A 2 weeks on and 1week off schedule of sunitinib is associated with decreased toxicity in metastatic renal cell carcinoma. European Journal of Cancer. 2014;50(6): 1084-9.
[27] Atkinson BJ, Kalra S, Wang X, Bathala T, Corn P, Tannir $\mathrm{NM}$, et al. Clinical outcomes in metastatic renal cell carcinoma patients treated with alternative sunitinib schedules. The Journal of Urology. 2014;191(3):611-8.

[28] Pan X, Huang H, Huang Y, Liu B, Cui X, Gan S, et al. Sunitinib dosing schedule $2 / 1$ improves tolerability, efficacy, and health-related quality of life in Chinese patients with metastatic renal cell carcinoma. Urologic Oncology: Seminars and Original Investigations. 2015;33(6): 268.e9-e15.

[29] Bracarda S, Iacovelli R, Boni L, Rizzo M, Derosa L, Rossi $\mathrm{M}$, et al. Sunitinib administered on $2 / 1$ schedule in patients with metastatic renal cell carcinoma: The RAINBOW analysis. Annals of Oncology. 2015;26(10):2107-13.

[30] Bjarnason GA, Khalil B, Hudson JM, Williams R, Milot LM, Atri M, et al. Outcomes in patients with metastatic renal cell cancer treated with individualized sunitinib therapy: Correlation with dynamic microbubble ultrasound data and review of the literature. Urologic Oncology: Seminars and Original Investigations. 2014;32(4):480-7.

[31] Choueiri TK, Escudier B, Powles T, Mainwaring PN, Rini BI, Donskov F, et al. Cabozantinib versus Everolimus in Advanced Renal-Cell Carcinoma. New England Journal of Medicine. 2015;373(19):1814-23.

[32] Motzer RJ, Hutson TE, Glen H, Michaelson MD, Molina A, Eisen T, et al. Lenvatinib, everolimus, and the combination in patients with metastatic renal cell carcinoma: A randomised, phase 2, open-label, multicentre trial. The Lancet Oncology. 2015;16(15):1473-82.

[33] Motzer RJ, Escudier B, McDermott DF, George S, Hammers HJ, Srinivas S, et al. Nivolumab versus everolimus in advanced renal-cell carcinoma. New England Journal of Medicine. 2015;373(19):1803-13.

[34] Lalani AA, McGregor BA, Albiges L, Choueiri TK, Motzer $\mathrm{R}$, Powles T, et al. Systemic treatment of metastatic clear cell renal cell carcinoma in 2018: Current paradigms, use of immunotherapy, and future directions. Eur Urol. 2019;75(1):100-10. 